E S T UDIOS 
BLANCO 
Revista de Ciencias Sociales - Número 62 (2013) - Páginas 13-37

La moral pública y los jueces

\section{LA MORAL PÚBLICA Y LOS JUECES}

PUBLIC MORALITY AND JUDGES

CARLOS MANUEL ROSALES*

Universidad Nacional Autónoma de México

cmr268@yahoo.com

\section{Resumen}

El presente trabajo analizará el fundamento moral para la aplicación de sanciones por las conductas que alteran y lesionan el orden público. Por lo que se estudiará el papel de los jueces al valorar y juzgar esos actos, bajo el principio del daño.

\section{Palabras claves}

Moral pública, libertad, autonomía individual, principio de daño, jueces.

\section{Abstract}

The present work will analyze the moral grounds to the application of sanctions for behaviors that alter and injure the public order. This essay will study the paper of the judges, when they judge and value those facts, under the principle of damage.

\footnotetext{
* Licenciado en Derecho por la Universidad Nacional Autónoma de México. Estudios de magister y Doctorado en la Universidad de Chile. Artículo recibido el 11 de marzo de 2013 y aceptado el 9 de mayo de 2013.
}

Revista de Ciencias Sociales - Número 62 (2013) - Universidad de Valparaíso - ISSN 0716-7725-Valparaíso, Chile 


\section{Keywords} judges.

Public morality, freedom, individual autonomy, principle of damage,

\section{Introducción}

La manera en cómo se conducen las personas en una sociedad, depende de varios factores como la costumbre, los valores comunes, la religión, la ley, etc. Pero la mejor manera de establecer parámetros de comportamiento "adecuado" son el consenso y el diálogo.

De esta forma, los temas que definen qué es lo "correcto", siempre contendrán una carga moral y, por tanto, serán susceptibles de crítica y de opinión ${ }^{1}$.

Existe una gran variedad de temas que se han estudiado en el campo de la deontología jurídica, como la prostitución, pornografía, racismo, libertad de expresión, aborto, eutanasia, entre otras².

En general, estos asuntos pueden ser vistos como una forma inocua de libertad individual, en el que cada persona puede disponer y gozar libremente de sus derechos. De esta manera, el derecho a ejercer, expresar y comunicar a otras personas nuestros pensamientos, ideas o sentimientos, es lo que reafirma la dignidad y el valor de toda persona como miembro de la sociedad, y lo que permite al individuo desarrollar todo su potencial ${ }^{3}$. Las motivaciones de cada sujeto, por lo que realiza estos actos puede tener varias fuentes como: el convencionalismo social, el placer, la necesidad de expresión, etc .

1. Cfr, PERRY, Michael J.: Constitutional rights, moral controversy and the Supreme Court. Ed. Cambridge, USA, 2009.

2. Cfr, DWORKIN, Ronald: Freedom's law, Ed. Harvard, Cambridge, 1996. PANICHAS, George: Sex, morality and the law, Ed. Routledge, Great Britain, 1997.

3. FAÚNDEZ LEDESMA, Héctor: Los límites de la libertad de expresión, Ed. UNAM, México, 2004, Pág. 45.

4. Vid. TEDFORD, Thomas L.: Freedom of speech in the United States, Ed. Strata, USA, 2009, págs. 153 y 223.

Facultad de Derecho y Ciencias Sociales - Universidad de Valparaíso - Chile 
Las conductas tienen su respaldo basado en lo subjetivo, y en el entendido de que se hace por convicción personal 5 . Por lo que, este comportamiento tiene una repercusión negativa, si los demás miembros de la comunidad consideran que esa conducta no refleja un valor común. Bajo este supuesto, la sociedad determina un conjunto de obligaciones generales, para que se garanticen y protejan los valores y/o principios que fomenten la conservación y unidad social.

Sin embargo, aunque las normas tengan el carácter de abstractas, generales e impersonales no siempre reflejan a toda la sociedad, por lo que siempre hay sujetos que muestran su inconformidad ${ }^{6}$.

Aquí yace el contrapunto: el tema de la moral pública (moralidad) y que determina principalmente, los valores que unen a un grupo social ${ }^{7}$. Estos lineamientos de conducta estipulan, indican y califican que es bueno, correcto o justo ${ }^{8}$; y que en caso de no cumplirse estos señalamientos, ese individuo deberá ser sancionado, con el objeto de inhibir la repetición de esa conducta, considerada como nociva9 ${ }^{9}$.

Este trabajo intentará averiguar cómo y por qué pueden o deben tolerarse o sancionarse las conductas individuales, que atenten contra el orden público y la moralidad; en qué casos y cuándo debe prohibirse alguna conducta y por último, cuál debe ser la valoración y decisión del juez al estudiar un asunto relacionado entre la autonomía individual y el respeto de la normatividad ${ }^{10}$.

5. RAWLS, John: Liberalism political, Ed. Harvard, Cambridge, 1996, págs. 5466.

6. HART, H.L.A.: Law, liberty and morality, Ed.Vintage, USA, 1963, pág. 3.

7. Cfr, JOYCE, Richard: The evolution of morality, The MIT press, USA, 2006.

8. Vid, MACKIE, J.L.: Ethics. Inventing the right and wrong, Ed. Penguin, USA, 1990, págs. 42-102.

9. TOCQUEVILLE, Alexis: La democracia en América, Ed. FCE, México, 1957, págs. 246 y ss.

10. BICKEL, Alexander M.: The least dangerous power, Ed. Yale press, USA, 1986, págs. 23-33, 58-59 y 199.

Revista de Ciencias Sociales - Número 62 (2013) - Universidad de Valparáíso - ISSN 0716-7725-Valparáiso, Chile 
Para comenzar este opúsculo, se analizará el tema de la moral pública. Por lo que se presentará cómo ha sido definida la misma. En este acápite, observaremos como las normas deben reflejar a la sociedad (en el contexto de un sistema democrático). Esto puede producir, la imposición de normas generales, que originan una facultad, obligación o una prohibición ${ }^{11}$; alimón que se debe instaurar una sanción, con el objeto de que esa conducta no se repita y se controle la conducta de los individuos en sociedad.

En el siguiente apartado, se presentará el concepto de libertad y el de autonomía individual. Por lo que analizaremos, si ciertos actos públicos basados en la libertad son una forma de placer, una representación artística, manifestación política, etc. y por otro lado, si esa conducta se deba reprimir y, si se permitiera, cuáles serían sus límites. Aquí nacen otros dos puntos fundamentales para la convivencia social, la tolerancia y el pluralismo ${ }^{12}$.

Por último, se estudiará la actuación que el juez debe ejercer al juzgar un comportamiento contrario a la moral pública. Pero qué pasa, si esa conducta está protegida por una norma superior, como la libertad de expresión ${ }^{13}$. En estos asuntos, el juzgador deberá ponderar los hechos y derechos, para deliberar y decidir entre sancionar esa conducta o proteger ese derecho ${ }^{14}$. O si la autoridad, debe tener cierta tolerancia hacia ciertas conductas; esto para tratar de obtener que algunos sujetos alcancen sus objetivos bajo ciertos estándares, y no la imposición absoluta de un grupo mayoritario ${ }^{15}$.

Este trabajo expondrá las aristas que rondan a esta discusión, con el ánimo de no producir un resultado liberal o normativo, o colocar

11. GARZÓN, Valdés Ernesto: "Algo más sobre la relación entre derecho y moral". En Vázquez, Rodolfo: Derecho y moral, op. cit., pág. 152.

12. FAÚNDEZ Ledesma, Héctor: op. cit., pág. 610.

13. Ídem, págs. 170-196.

14. POSNER, Richard: How judges think, Ed. Harvard, USA, 2008, Pág. 175.

15. FALLON, Richard Jr.: The dynamic constitution, Ed. Cambridge, USA, 2004, pág. 1.

Facultad de Derecho y Ciencias Sociales - Universidad de Valparaíso - Chile 
a los jueces como verdugos de la autonomía individual o como censores y protectores de la moral pública; sino con el objetivo, de que cada lector tenga la oportunidad y los elementos para conocer, valorar y elucidar el tema expuesto.

\section{Moral pública}

El diccionario Black's Law define a la moral pública como: "1. Conjunto de ideales o creencias generales morales de una sociedad. 2. Ideales o acciones de un individuo que se extienden y afectan a otros. La ley moral está comprendida por una colección de principios que definen una buena o mala conducta; o un estándar, por el que una acción debe conformarse para tener razón o ser virtuosa" ${ }^{16}$.

La finalidad de la moralidad es encontrar un conjunto de principios que sean justamente aceptables para la comunidad, que tengan aplicaciones y consecuencias prácticas para determinada sociedad $^{17-18}$.

Es fundamental señalar, que ningún problema puede ser tratado de forma universal, pues las circunstancias que rodean a cada asunto son particulares, dentro de un contexto histórico, político, social o económico. Por lo que se convierte de una vital importancia las condiciones socio-políticas, mismas que difieren en cada caso, lugar, momento o circunstancia ${ }^{19}$.

16. Ed. West, USA, 2009, pág. 1100.

17. MACKIE, J.L.: op. cit., págs. 105-193.

18. Para John RAWLS es el equilibrio reflexivo lo que permite a cada individuo determinar qué es lo bueno, correcto o justo. Political liberalism, op. cit., págs. 8, 28, 72, 89 y 95-96, "The outcome of reflective thought and reasoned judgment, the ideals, principles, and standards that specify our basic rights and liberties, and effectively guide and moderate the political power to which we are subject. This is the outer limit of our freedom”. Ídem, págs. 222, 242, 384 y 388.

19. NOHLEN, Dieter: El contexto hace la diferencia: reformas institucionales y el enfoque histórico-empírico, Ed. UNAM, México, 2003, págs. 191 y 196.

Revista de Ciencias Sociales - Número 62 (2013) - Universidad de Valparáíso - ISSN 0716-7725-Valparaíso, Chile 
Entonces, se tiene que a partir de cierto contexto histórico, se crean y/o seleccionan los valores, principios y objetivos que han de regir a un Estado. Por lo que la norma (idealmente) es el producto de una comunidad en un contexto determinado.

Las normas constituyen creaciones culturales a través de las que los hombres tratan de preservar los principios comunitarios relevantes o con una jerarquía explicada en el contexto mismo (según sea el tiempo y espacio en cuestión). Con esto debemos de ubicar cada asunto en cada contexto, para poder entender el escenario de cada sociedad ${ }^{20}$.

Para fines de este trabajo, propongo ubicarnos como escenario un Estado constitucional democrático estable, en el que estén reconocidos los Derechos Humanos (DDHH), que permita la representación y participación del pueblo en los asuntos públicos; que se encuentren bien determinadas las funciones de todos los órganos del Estado, para que no abusen del poder, y el Estado no tenga ninguna discreción ilimitada para decidir qué medidas son las apropiadas para preservar el orden público ${ }^{21}$.

A partir de este contexto democrático representativo, los legisladores elaborarán las normas que conllevarán a la finalidad de esa sociedad, generando un ideal de conducta pública para todos los habitantes ${ }^{22}$.

"Esta forma de conocimiento que construye una representación simplificada del mundo y de sus procesos, representación que parte generalmente de ciertos supuestos sobre la realidad, que no pueden ser demostrados, los cuales permanecen prácticamente incambiados a lo largo de un período importante de tiempo"23.

20. HINDE, Robert A.: Why good is good. The sources of morality, Ed. Routledge, USA, 2002, págs. 45-150.

21. FAÚNDEZ Ledesma, Héctor: op. cit., pág. 591.

22. DE LOS CAMPOS, Hugo: http://ciberconta.unizar.es/leccion/sociodic/ tododic.pdf

23. Vid, WINDLESHAM, Lord: Politics, punishment and populism, Ed. Oxford, USA, 1998, págs. 100-147.

Facultad de Derecho y Ciencias Sociales - Universidad de Valparaíso - Chile 
Con esta base de imponer la ideología de cierto grupo político en el poder, se determinan las conductas que pueden realizar las personas $^{24}$. Esta conducta abarca todo conjunto de acciones y omisiones externas de un ser viviente ${ }^{25}$.

La política proporciona varias clases de mecanismos para abrirse camino de la indecisión a la acción. Estos mecanismos raras veces implica el uso desapasionado de razón pura a decisiones prácticas. De hecho, la política democrática contiene procedimientos totalmente institucionalizados, como el voto de mayoría, para alcanzar decisiones cuando la razón ha fallado en determinar un curso de acción ${ }^{26}$. Esto puede significar sólo que la política, con su acompañamiento invariable, el uso del poder, entra en juego cuando la razón se ha llevado a su finn ${ }^{27}$. Con esta idea, se constituye la idea del orden público con la que se va a hacer prevalecer el interés colectivo por encima del interés individual ${ }^{28}$.

Lo anterior permitirá producir una obra de ingeniería, que estará dirigida a la Socialización; esto con el objetivo de que una comunidad enseñe a "descubrir a sus nuevos integrantes, las normas, valores y creencias que ellos mismos guardan en lo más profundo de su ser, como signo de su individualidad, y que invariablemente coinciden con las normas, valores y creencias que profesa la comunidad en que habitan"29. Por lo que también se debe estipular, qué conductas serán contrarias a los valores morales, que afecten o dañen a la comunidad ${ }^{30}$.

24. ACKERMAN, Bruce: We the people. Foundations, Ed. Harvard press, USA, 1991, pág. 224.

25. SCHOECK, Helmut: Diccionario de sociología, Ed. Herder, Barcelona, 1981, pág. 134.

26. SCRUTON, Roger: The Palgrave Macmillan Dictionary of Political Thought, USA, 2007, pág. 452.

27. WILLIAMS, Melissa and WALDRON, Jeremy: Toleration and its limits, Ed. New York University press, New York, 2008, pág. 369.

28. FAÚNDEZ Ledesma, Héctor: op. cit., págs. 568, 592 y 594.

29. DE LOS CAMPOS, Hugo: http://ciberconta.unizar.es/leccion/sociodic/ tododic.pdf Vid, FETNER, Gerald: Ordered liberty, Borzoi books, USA, 1983, pág. 32.

30. Las prohibiciones basadas en la apelación a valores morales, la comunicación de esos mismos valores, son uno de los principales canales de represión y

Revista de Ciencias Sociales - Número 62 (2013) - Universidad de Valparáíso - ISSN 0716-7725-Valparaíso, Chile 
Pero estas normas tienen un origen democrático, que se basa no a partir de una simple imposición ${ }^{31}$; sino que son originadas a partir de la delegación de algunas personas, que los representarán y con ellos, se logre un consenso para determinar y conseguir los elementos que permiten conseguir sus objetivos ${ }^{32}$.

"Las fuentes que hacen posible la autoridad de las normas son solamente dos: una, la aceptación de la regla como patrón de conducta en una comunidad determinada, pero no simplemente como pauta a seguir sino como práctica obligatoria...La otra fuente de autoridad es justamente la norma secundaria fundamental, porque de allí derivan su validez bajo las reglas que han sido elaboradas de acuerdo a los procedimientos legislativos" ${ }^{\prime 3}$.

El trabajo legislativo deberá inferir qué principios y valores que contendrán la normatividad ${ }^{34}$. "Lo que es moralmente correcto, lo que debe procurarse y defenderse, aquello a lo que debe aspirar el espíritu humano" 35 .

canalización de pulsiones instintivas conforme a la naturaleza de la moral, consistente en la formación de una voluntad que no tiene cuenta deseos, necesidades o intereses de ninguna otra naturaleza. GALLINO, Luciano: Diccionario de sociología, Ed. Siglo XXI, México, pág. 594.

31. RAZ, Joseph: op. cit., págs. 193-216.

32. JEFFERSON Powell: H., op. cit., p. 110. FETNER, Gerald: op. cit., pág. 144.

33. SALMERÓN, Fernando: "Sobre moral y derecho". En Vázquez, Rodolfo, Derecho y moral: op.cit., pág. 97. Randy BARNETT estima que la legitimidad de las normas se obtiene por el proceso de elaboración de las mismas; por lo que, cuando los legisladores más se ajusten y respeten al procedimiento legislativo, más legítimas serán las normas producidas. Restoring the lost constitution, Ed. Princeton press, USA, 2004.

34. HART, H.L.A.: op. cit., pág. 6.

35. DE LOS CAMPOS, Hugo: http://ciberconta.unizar.es/leccion/sociodic/ tododic.pdf

Facultad de Derecho y Ciencias Sociales - Universidad de Valparaíso - Chile 
"La palabra norma no se entiende aquí como esa media o percepción modal que se forma cuando algunos grupos de personas afrontan juntos una situación ambigua. En un primer momento, esos grupos se encuentran con interpretaciones divergentes de esa situación, que va clarificándose gradualmente, de forma que en este proceso de convergencia se obtiene, finalmente, una norma, es decir, una convergencia genuina de las percepciones de la media (o percepciones modales), opiniones o acciones de los miembros del grupo racial. Es más común el concepto de norma para significar un estándar o criterio con que juzgar el carácter o la conducta de un individuo, de cualquier función o expresión de la vida social. A su vez, norma social indica en concreto el modo como debe comportarse el individuo o el grupo en las más variadas situaciones, la prescripción de cómo un individuo o un grupo social debe o no debe pensar, sentir o actuar en determinadas situaciones. Tales normas adquieren en la práctica la forma de una serie o conjunto de reglas sobre cualquier aspecto del comportamiento humano social. Existen, por tanto, normas políticas, legales, religiosas, científicas, etcétera, que forman un continuum muy amplio, para indicar que ciertas formas de conducta están permitidas, recomendadas, absolutamente exigidas, desaprobadas o positiva y categóricamente prohibidas. Cualquier desviación de la norma suele ir seguida por alguna sanción o premio"36.

Por lo que se ha hecho necesario la creación de normas, primero para la supervivencia de la sociedad ${ }^{37}$; segundo, para cubrir sus exigencias, y tercero, para que existan mecanismos legales para la lucha por el poder entre los distintos grupos políticos ${ }^{38}$.

"En definitiva, el orden normativo se ha ido desarrollando como parte de la sociedad humana; porque la ha ayudado a satisfacer las

36. FRANCO Demarchi, Aldo Ellena: Diccionario de sociología, Ed. Paulinas, Madrid, 1986, pág. 1174.

37. BICKEL, Alexander: op. cit., Pág. 38. GARLAND, David, La cultura del control, Gedisa, España, 2001, págs. 71-106.

38. KOJÉVE, Alexandre: La noción de autoridad, Ed. Nueva visión, Buenos Aires, 2005, pág. 36. LINZ, Juan J.: Problems of democratic transition and consolidation, Ed. The Johns Hopkins University, USA, 1996, pág. 5.

Revista de Ciencias Sociales - Número 62 (2013) - Universidad de Valparáíso - ISSN 0716-7725-Valparáiso, Chile 
necesidades sociales fundamentales, permitiendo sobrevivir de esta forma a la sociedad y, por tanto, a la especie humana. Sólo mediante un sistema elaborado de obligaciones morales puede sobrevivir el individuo y, por tanto, la sociedad. Por otra parte, la sociedad humana depende del modo como cada miembro de la misma cumple sus tareas, a la vez que los demás miembros cumplen las restantes. Cada uno debe tener la garantía de que los demás cumplan sus cometidos, mientras él cumple el suyo. Son las normas sociales las que controlan al individuo para que cumpla lo que el grupo espera de él. El orden social se basa en estas normas" ${ }^{39}$.

El rol del legislador será plasmar en las leyes, los valores morales de la comunidad; con esto se elaboran ciertas pautas de control para la sociedad $^{40}$.

"El control social de una sociedad o de un grupo aspira solamente a que se observen regularmente aquellas reglas de comportamiento que están de acuerdo con la moral vigente. Las sociedades pueden juzgar y controlar casi todo el comportamiento de sus miembros según las leyes de una moral declarada dogmáticamente como obligatoria. Sin embargo, por regla general, la moral de una sociedad se extiende solamente a una parte de las formas de comportamiento posibles” ${ }^{41}$.

Toda sociedad organizada tiene el derecho a proteger los valores morales prevalecientes, y a defenderse de aquellas expresiones que ofendan los sentimientos de la comunidad ${ }^{42}$.

Con lo anterior, se estructuran los esquemas de conducta que determinan las regularidades y uniformidades en el comportamiento $\operatorname{social}^{43}$. Lo peor que puede suceder para un esquema de conducta pueda ser aceptado como conducta en la respectiva cultura es que un Individuo

39. FRANCO Demarchi, Aldo Ellena: op. cit., pág. 1174.

40. HART, H.LA: op. cit., págs. 14 y 20.

41. SCHOECK, Helmut: Diccionario de sociología, Ed. Herder, Barcelona, 1981, pág. 474.

42. FAÚNDEZ Ledesma, Héctor: op. cit., pág. 599.

43. HART, H.L.A.: op. cit., pág. 71.

Facultad de Derecho y Ciencias Sociales - Universidad de Valparaíso - Chile 
defraude las expectativas de conducta de un número bastante grande de personas ${ }^{44}$.

De esta forma, cuando los legisladores prohíben cierto comportamiento mediante una disposición legal, "está diciendo que dicha acción es en cierto modo, y sobre cierta base, reprensible o susceptible de desaprobación" ${ }^{45}$.

Además, es necesaria que esa conducta sea rechazada por la mayoría de la sociedad, "es necesario que provoque un verdadero sentimiento de reprobación, de repugnancia" ${ }^{46}$. Por lo que el castigo, se convierte en "un acto expresivo y simbólico, expresivo de una actitud de grave desaprobación de lo hecho por la persona castigada sobre la base de que es considerada culpable por ello" ${ }^{47}$.

Sin duda, toda sociedad tiene el derecho a usar sus leyes como un acto de autodefensa para su integridad y supervivencia ${ }^{48}$. De lo pretérito, se desprende que toda conducta humana se reduce, por tanto, a un conjunto de reflejos condicionados.

Hay que considerar, que varios estudiosos (Alexy, Dworkin, MacIntyre, Nagel, Sandel, Taylor y otros) tratan de empatar la moral con el derecho y se “....abre la posibilidad de remplazar a la moral como norma de vida — en el sentido de criterio último de conducta-, reduciendo de esta manera espacios de libertad de los individuos, para pasarlas a cargo del derecho" ${ }^{49}$. Pero no significa que se deba tener una

44. http://www.law.yale.edu/documents/pdf Comella_Do_Constitutional_ Rights_Bind_Private_Individuals.pdf

45. MACCORMICK, Neil: "En contra de la ausencia de fundamento moral. En Vázquez, Rodolfo, Derecho y moral, op. cit., pág. 174. HART, H.L.A: op. cit., págs. 55-59.

46. MALEM, Jorge: op. cit., pág. 63.

47. MACCORMICK, Neil: op. cit., pág. 173. FALLON, Richard Jr.: op. cit., pág. 39.

48. RAZ, Joseph: The morality of freedom, Ed. Oxford, New York, 1988, págs. 2399.

49. SALMERÓN, Fernando: op. cit., Pág. 83. FAÚNDEZ Ledesma, Héctor: op. cit.: Pág. 599.

Revista de Ciencias Sociales - Número 62 (2013) - Universidad de Valparáíso - ISSN 0716-7725-Valparáiso, Chile 
obediencia ciega ${ }^{50}$. "La única finalidad por la cual, el poder puede con pleno derecho, ser ejercido sobre un miembro de la comunidad civilizada contra su voluntad, es evitar que perjudique a los demás"

Por lo mismo, las normas deben contar con "una concepción objetivista de la norma parece ser un medio adecuado para otorgar a la voluntad del dador de la norma algo así como una legitimación inobjetable y con ello la deseada presión” ${ }^{52}$.

Del incumplimiento de las normas vendrá en consecuencia para el infractor, un castigo aprobado por la sociedad: ${ }^{53}$ "La justificación moral del castigo depende, en última instancia, del carácter dañino de la acción que se reprime" 54 .

Con la imposición de la sanción, se desarraiga e inhibe la conducta personal, limitando su actuación social: "opera como un elemento disuasorio directamente en contra de lo que se cree correcto, o al menos como una fuerza coactiva en contra de que uno haga algo, que en principio parece moralmente aceptable, y quizá preferible en determinado contexto" 55 .

Así, la moral pública se ha convertido en la circunstancia que con más frecuencia se invoca para coartar las libertades ${ }^{56}$. Por consiguiente, la moral pública debe valorarse en su justa medida, sin utilizarla como vehículo para imponer prejuicios y sentimientos ${ }^{57}$.

50. GARZÓN Valdés, Ernesto: op. cit., pág. 157.

51. MALEM, Jorge: op. cit., pág. 61.

52. BULYGIN, Eugenio: "Hay vinculación necesaria entre derecho y moral?". En Vázquez, Rodolfo: Derecho y moral, op. cit., págs. 228, 229 y 231.

53. KOJÉVE, Alexandre: op. cit., pág. 38. BICKEL, Alexander M.: op. cit., págs. 69-70, y 236.

54. MALEM, Jorge: op. cit., pág. 72. Vid, http://www.uns.edu.ar/programma/ ediciones/edicion1/07_edicion1.pdf Este tema lo refiere Robert ALEXY, como "el argumento de la corrección”. En Vázquez, Rodolfo: Derecho y moral, op. cit., pág. 122.

55. MACCORMICK, Neil: op. cit., pág. 166.

56. FAÚNDEZ Ledesma, Héctor: op. cit., pág. 598.

57. Ídem, págs. 599, 601, 605 y 606.

Facultad de Derecho y Ciencias Sociales - Universidad de Valparaíso - Chile 
Lo fundamental, es que cuando se crea, modifica o reforma una norma jurídica se piensa que esta tiene un fin justo, que contiene un espíritu de justicia; determina qué es lo correcto; que es vigente y aceptada, porque su valor, se apoya y genera de la voluntad general ${ }^{58}$.

Retomando nuestro tema principal, debemos discernir porqué se prohíben algunas conductas. La respuesta a priori sería que existe una norma que la prohíbe y castiga. Esta conducta es desaprobada, porque la mayoría de la sociedad no cree que ese comportamiento refleje los valores sociales que la unen, por lo que se debe sancionar al sujeto que transgrede ese valor moral. Aquí nace la imposición de conducta en los lugares públicos, pues no es de interés para la sociedad, lo que cada persona realiza en su privacidad. Pero lo que si afecta o daña a la sociedad, debe ser reprendido como muestra de repugnancia.

La coincidencia entre las normas y los miembros de la sociedad es la que permite la convivencia ideal ${ }^{59}$. Pero si la normatividad es violada (supuestamente), la persona deberá sujetarse a ser juzgada, por un operador jurídico, que determinará si se transgredió la seguridad, un bien o un interés de la sociedad ${ }^{60}$.

Esto nos conlleva a que no solo basta produzca una conducta perjudicial, y que se contemple un castigo ${ }^{61}$. Sino que debe existir un individuo que juzgue, si ese comportamiento es contrario a las normas y las costumbres sociales, para poder restablecer el orden o defender algún abuso ${ }^{62}$.

Pero de qué manera los jueces pueden o deben expresar la desaprobación de la sociedad; si bien "es cierto que ellos expresan la

58. FISS, Owen: Libertad de expresión y estructura social, Ed. Fontamara, México, 2004, pág. 59.

59. SALAZAR, Pedro: "Justicia constitucional y democracia”, en Vázquez, Rodolfo: Corte, jueves y política, Ed. Fontamara, México, 2007, pág. 39.

60. LARMORE, Charles: The autonomy of morality, Ed. Cambridge, USA, 2008.

61. CRAGG, Wesley: The practice of punishment, Ed. Routledge, London, 1992, págs. 115-137.

62. ACKERMAN, Bruce: op. cit., pág. 283.

Revista de Ciencias Sociales - Número 62 (2013) - Universidad de Valparaíso - ISSN 0716-7725-Valparaíso, Chile 
condena del Estado ante los actos que la legislación estatal califica de delitos; y una actitud de condena o desaprobación es per se una actitud moral” ${ }^{3}$.

Con este marco, podemos advertir cuáles son los valores que le interesan tutelar a esa comunidad. Sin embargo, no siempre las leyes reflejan la individualidad. Pues es la autonomía la que nos permite elegir. Esto, lo hacemos a partir de decidir qué metas planea cada persona, qué gustos tiene, la determinación personal de cómo vivirá, etc. Todo esto a partir de su libertad y autonomía individual.

\section{Libertad y autonomía individual}

Uno de los conceptos más aceptado y utilizado sobre el tema de la libertad, es el de Isaiah Berlin ${ }^{64}$. Este autor clasifica a la libertad en negativa y positiva. La noción de libertad negativa es aquella que se da por la imposición de otra persona; con esta limitación se frustran sus ilusiones ${ }^{65}$. En este espacio, no existe una normatividad que rijan las relaciones sociales; como sucede en la esclavitud o la pobreza económica. $\mathrm{Al}$ contrario, la libertad positiva nos permite ser dueños de nuestro destino, se desarrolla el principio de autonomía. Aquí se encuentra, el sentido de la libertad con base en el valor y en el sentido de la normatividad $^{66}$.

La libertad ordenada permite ubicar que ciertas conductas políticas y morales se realicen libremente, sobre las bases de las leyes expedidas por el dominio legislativo de los Estados ${ }^{67}$. Por lo que la

63. MACCORMICK, Neil: op. cit., pág. 175.

64. BERLIN, Isaiah: Four essays on liberty, Ed. Oxford, England, 1969, págs. 118172.

65. Vid, ROTHBARD, Murray N.: The ethics of liberty, Ed. New York University, USA, 1998, Págs. 201 y ss.

66. Cfr, DWORKIN, Ronald: Freedom's law, págs. 214-216. FAÚNDEZ Ledesma, Héctor: op. cit., pág. 753.

67. FETNER, Gerald: op. cit., pág. 73.

Facultad de Derecho y Ciencias Sociales - Universidad de Valparaíso - Chile 
libertad no es una serie de puntos aislados expuestos en términos de libertad (expresión, prensa y religión y otros tantos). Esta es una continuidad racional que, hablando ampliamente, incluye una libertad de todas las imposiciones arbitrarias e intentos para restringirla ${ }^{68}$.

La tradición de la libertad de expresión constituye sobre esta visión del mundo cuando reduce la libertad de expresión a la autonomía, y define a la autonomía para significar la ausencia de interferencia gubernamental ${ }^{69}$.

La autonomía personal es definida como: "El principio jurídico filosófico que les atribuye a los individuos un ámbito de libertad, dentro del cual pueden regular sus propios intereses; permitiéndoles crear relaciones obligatorias entre ellos que deberán ser reconocidas y sancionadas en las normas de derecho" ${ }^{70}$.

En la teoría del derecho, las discusiones sobre la autonomía surgen frecuentemente en el contexto de los debates acerca de la imposición de la moral a través de la legislación, donde aquellos que creen que la autonomía es un valor fundamental demandan que las acciones del Estado no restrinjan el rango de modos de vida disponibles a los ciudadanos ${ }^{71}$.

Sin embargo, no sólo se trata de seleccionar un proyecto de vida ${ }^{72}$. Esta decisión se debe realizar con base en la convivencia social, que se rige por normas jurídicas ${ }^{73}$.

68. FALLON, Richard Jr.: op. cit., pág. 138.

69. FISS, Owen: op. cit., págs. 29 y 51. RAZ, Joseph: op. cit., págs. 369-429.

70. CORNEJO, Certtucha, Francisco: Voz "Autonomía de la voluntad", Diccionario Jurídico Mexicano, Tomo I Ed. UNAM, México, 1982, págs. 239-240.

71. BIX, Brian H.: Diccionario de teoría jurídica, Ed. UNAM, México, 2009, pág. 22.

72. FETNER, Gerald: op. cit., Pág. 134. Vid, GARGARELLA, Roberto: "El carácter igualitario del republicanismo”. En Isegoria, No 33, 2005, págs. 175-189.

73. POSNER. Eric: Law and social norms, Ed. Harvard press, USA, 2002, págs. 203-224.

Revista de Ciencias Sociales - Número 62 (2013) - Universidad de Valparáíso - ISSN 0716-7725-Valparaíso, Chile 
Si contamos con un sistema democrático liberal, se dará preponderancia a potenciar las libertades individuales ${ }^{74}$. "En la parte que le concierne meramente a él, su independencia es de derecho, absoluta. Sobre sí mismo, sobre su cuerpo y espíritu, el individuo es soberano" 75 . El problema es definir cuáles son los límites a esas libertades ${ }^{76}$ :

"La libertad no sólo hace posible que nos demos a nosotros mismos nuestra propia ley, sino también hace posible que seamos capaces de cumplirla o incumplirla" ${ }^{77}$.

Con esta determinación se indican los lineamientos de conducta individual. Pero el problema acaece cuando el sujeto no se siente identificado con la norma ${ }^{78}$. Aquí su razonamiento, le mostrará que esas imposiciones están basadas en prejuicios que no concuerdan con su libre voluntad.

Pero veamos el concepto de prejuicio, para entender el cisma entre libertad e imposición.

“Calificativo para designar todo juicio, acerca de una cosa, que se haya emitido sin respetar en su formulación, las reglas del sano juicio (que no son otras que las que dicta la ciencia moderna). Refiere por tanto,

74. FALLON, Richard Jr.: op. cit., pág. 33. La tesis principal del Estado liberal es respetar y proteger los derechos tanto de individuos como de grupos, establecer la justicia y la igualdad entre sus ciudadanos y asegurar la aplicación de la ley.

75. MALEM, Jorge: op. cit., pág. 60.

76. El problema de la libertad ha sido preocupación de filósofos y monarcas desde el origen de los tiempos. A lo largo de la historia se han sucedido distintos principios sobre la libertad. DE LOS CAMPOS, Hugo: Diccionario de Sociología, http://ciberconta.unizar.es/leccion/sociodic/tododic.pdf Página web, consultada el 20 de noviembre del 2012.

77. MUGUERZA, Javier: "El tribunal de la conciencia y la conciencia del tribunal”. En Vázquez, Rodolfo: Derecho y moral, op. cit., pág. 185.

78. FISS, Owen: op. cit., pág. 84.

Facultad de Derecho y Ciencias Sociales - Universidad de Valparaíso - Chile 
bien a juicios que se hayan emitido sin respetar regla alguna, bien a juicios que surjan de la aplicación de reglas de conocimiento distintas a las del sano juicio" 79 .

La finalidad del prejuicio es considerar de forma explícita, si una persona o grupo social es objeto de éste, se debe tan sólo por las características realmente negativas de esa persona o grupo. Es ésta una afirmación tautológica, autorrealizadora: las características negativas de los demás inducen a desarrollar un prejuicio negativo, por lo que, si un grupo es objeto de prejuicio, sus características son necesariamente negativas ${ }^{80}$.

Entonces, se observa que las condiciones sociales impuestas por la mayoría sirven como control social ${ }^{81}$; que se da a partir del supuesto, de que el sujeto no se comportara de acuerdo con los códigos morales interiorizados ${ }^{82}$.

Aquí nace otro tema en nuestro conflicto, el de la Tolerancia que deben de tener los demás elementos de la sociedad ante una conducta que se debe de reprender. La moralidad aplica la forma general de tolerancia como una relación entre motivos para motivos de acción para la desaprobación, y razona para refrenarse en la expresión o la interpretación sobre aquella desaprobación.

Así, tenemos por un lado la libertad de pensamiento que etiqueta a algunas imposiciones como condicionamientos sociales, y por el otro lado, el control que se debe ejercer sobre todos los miembros de una comunidad, para una convivencia pacífica. Por lo que el justo medio es la Tolerancia.

79. http://enciclopedia_universal.esacademic.com/19830, página consultada el 22 de noviembre de 2012 .

80. FRANCO Demarchi, Aldo Ellena: op. cit., pág. 1364.

81. Vid, MELOSSI, Dario: El Estado del control social, Ed. Siglo XXI, México, 1982, Págs. 160-191 y 231-255.

82. GALLINO, Luciano: Diccionario de sociología, Ed. Siglo XXI, México, pág. 594.

Revista de Ciencias Sociales - Número 62 (2013) - Universidad de Valparáíso - ISSN 0716-7725-Valparáiso, Chile 
"La tolerancia significa renuncia en la prevención de algunos males, justificada por el riesgo de que si no pueden forzar sería peor. La tolerancia de los disidentes es por lo tanto, aceptada como un mal necesario, cuando no es posible suprimir la disidencia, es decir, un mal menor cuando el costo de la represión llevaría a un exceso. Está claro que en este caso, el concepto de tolerancia es un grado preparatorio del principio de libertad: la tolerancia de ajuste, de hecho, un espacio de inmunidad en las decisiones de las personas, pero se califica como una concesión revocable e irrevocable de la ley" ${ }^{33}$.

Es preciso elucidar que la Tolerancia "contiene un componente relativista e historicista del pensamiento liberal. Su naturaleza es pluralista y conduce al reconocimiento de posiciones contrastantes, dentro de un sistema de problemas disciplinado por las reglas del juego" ${ }^{44}$.

La tolerancia es el respeto a las ideas, creencias o prácticas de los demás cuando son diferentes o contrarias a las propias ${ }^{85}$. La tolerancia debe ser reconciliada con el deber de formar el carácter para lo mejor, y promover el progreso de la comprensión moral, cambiando argumentos críticos con aquellos con quien se discrepa. Por lo que debe ser entendida como el acto o práctica de permitir algo, no totalmente aprobado; o como el acto o práctica de permitir algo de manera que no dificulte la convivencia, que permite opiniones y creencias (en particular en materia religiosa), que se diferencian de las normas predominantes ${ }^{86}$.

Asimismo, la tolerancia es reconocida como el grado en que aceptamos racionalmente las cosas que desaprobamos personalmente. Esto desde luego describe la práctica de tolerancia, no la virtud. Incluso cuando un acto dado de tolerancia puede ser descrito sin controversia (que es no siempre), la clase de desaprobación de un actor dado, y las motivaciones que ella tiene para actuar sobre ello, puede variar ${ }^{87}$.

83. Ídem.

84. BOBBIO, Norberto: Dicionário de política, Ed. UnB, 11ª . Edición, Brasil, 1983, págs. 1245-47.

85. Real Academia de la Lengua Española.

86. BLACK'S LAW: Ed. West, USA, 2009, pág. 1625.

87. WILLIAMS, Melissa and WALDRON, Jeremy: op. cit., pág. 224.

Facultad de Derecho y Ciencias Sociales - Universidad de Valparaíso - Chile 
De esta forma, la tolerancia se convierte en el acto positivo de la no interferencia, con la obligación del otro a pesar de la respuesta negativa de alguien. Esto es un acto unilateral de una persona hacia el otro, un acto que debe ser considerado un valor, una virtud o un principio $^{88}$.

Entonces la tolerancia consiste en una lista larga que distingue y permite: "compromiso, paz o coexistencia, indiferencia, escepticismo, reconocimiento, aceptación, indulgencia, liberalidad, paciencia, resistencia, condonación, caridad, respeto, pluralismo, y más" ${ }^{\prime 9}$.

Una persona puede actuar tolerantemente en relación con sus creencias, aun cuando aquellas no puedan ser objetivamente verdaderas, o pueden ser objetivamente falsas, tal como alguien puede actuar racionalmente en relación con creencia falsas ${ }^{90}$.

La tolerancia se convierte en un tema relevante, cuando las sociedades que eran comunidades monolíticas de fe y de valor. Estos temas crearon diferentes sectas y partidos, haciendo que los individuos y familias vivieran por separado de las otras comunidades, y que posteriormente, convivieron en un solo entorno social y político ${ }^{91}$. La tolerancia permite la dirección de la diversidad, que busca la coexistencia; esto sirve como la relación entre las personas ante la diversidad.

Es en este punto donde ocurre el choque de lo individual con lo general: los prejuicios y la Tolerancia:

"Los motivos que parecen justificar diferencias en los prejuicios, pueden resumirse en algunos puntos esenciales: a) cada individuo, durante el proceso de socialización, sufre una exposición diferenciada a las normas culturales, la cual se traduce en diferencias en las estructuras individuales del prejuicio; b) en todo sistema social complejo existen diversos subsistemas culturales, cada uno de los cuales

88. $\quad$ Ídem., pág. 316.

89. Ídem, pág. 180.

90. Ídem, Pág. 380.

91. Ídem, págs. 24 y 321.

Revista de Ciencias Sociales - Número 62 (2013) - Universidad de Valparaíso - ISSN 0716-7725-Valparaíso, Chile 
tiene su modelo normativo propio y específico, que se concreta, además, en modelos diferenciados de prejuicio; c) la presión a favor de la conformidad con las normas culturales no es absolutamente rígida, pues permite una gama de comportamientos aceptables, que permiten la manifestación de diferencias individuales; $d$ ) dentro del mismo sistema — o subsistema — cultural, las diferencias individuales pueden obedecer a diversas necesidades y rasgos de la personalidad y/o a las diversas funciones que desempeña el prejuicio en relación con las necesidades psíquicas individuales. Entre las funciones psíquicas que el prejuicio desempeña en el individuo, se pueden citar, a modo de ejemplo, la justificación de una hostilidad patológica, la racionalización de deseos y comportamientos culturalmente desaprobados para realizar aspiraciones culturalmente aceptables, la satisfacción supletoria de deseos reprimidos, la protección de sentimientos de autoestima, la defensa contra amenazas a la autoestima, la justificación para poder conseguir un status social más elevado o la racionalización de las condiciones de inferioridad. En cuanto a los rasgos de la personalidad, se pueden resumir en las diversas situaciones individuales de inseguridad y ansiedad y en los diversos modos de hacerles frente" ${ }^{92}$

Retomando nuestro tema, bajo estos cánones, podemos dilucidar que si bien toda persona tiene el derecho de criticar las normas impuestas y elaborar un conjunto de principios de actuación, se debe reconocer que los mismos sólo deben de regir en sus actos personales, sin perjudicar a los demás ${ }^{93}$. Por lo que ahora, se debe exponer y justificar por qué se debe ejercer la represión a ciertas expresiones personales.

Con este tema comenzaremos nuestro siguiente apartado; el papel de los jueces en la protección de la moral pública y la tutela judicial a las libertades individuales

\section{El principio de daño como instrumento para sancionar asuntos de orden público}

Los jueces son los responsables de restablecer el orden alterado, e imponer la sanción ante una violación a la normatividad ${ }^{94}$. Esto a primera vista no parece tan complicado; sin embargo, hay casos que no

92. FRANCO Demarchi, Aldo Ellena: op. cit., pág. 1360.

93. FAÚNDEZ Ledesma, Héctor: op. cit., pág. 608.

94. FALLON, Richard Jr.: op. cit., pág. 198.

Facultad de Derecho y Ciencias Sociales - Universidad de Valparaíso - Chile 
solo se trata de encuadrar una conducta con un tipo legal, para poder castigar al infractor ${ }^{95}$. Existen asuntos en que se deben de ponderar los derechos fundamentales con las normas legales, teniendo que valorar con algo más que las leyes ${ }^{96}$ :

"Los casos trágicos plantean problemas de conciencia a los jueces y tribunales, como trágico es el conflicto entre la ley y la conciencia, entre el derecho y la justicia, entre el ser jurídico o legal y el deber ser político o moral" ${ }^{\prime}$.

Lo que es una obligación y deber de los tribunales es "decidir de acuerdo a lo que consideran mejor y más justo desde el punto de vista moral" ${ }^{\prime 8}$. Pero el juez, tiene la facultad de encontrar el sentido moral de una norma o deben actuar mecánicamente ${ }^{99}$ ? Así, para calificar un hecho dentro de la tolerancia moral debe haber alguna razón, creencia o conducta que se considera socialmente equivocada ${ }^{100}$.

Se vuelve necesario recordar que "en la moral no hay reglas que establezcan autoridades y procedimientos cuyo fin sea la creación, modificación o supresión de normas morales" ${ }^{101}$. Por lo que se tiene que dar un castigo, cuando se viola una norma que contiene un valor moral ${ }^{102}$, el juez debe considerar y ponderar con base en el principio del daño ${ }^{103}$.

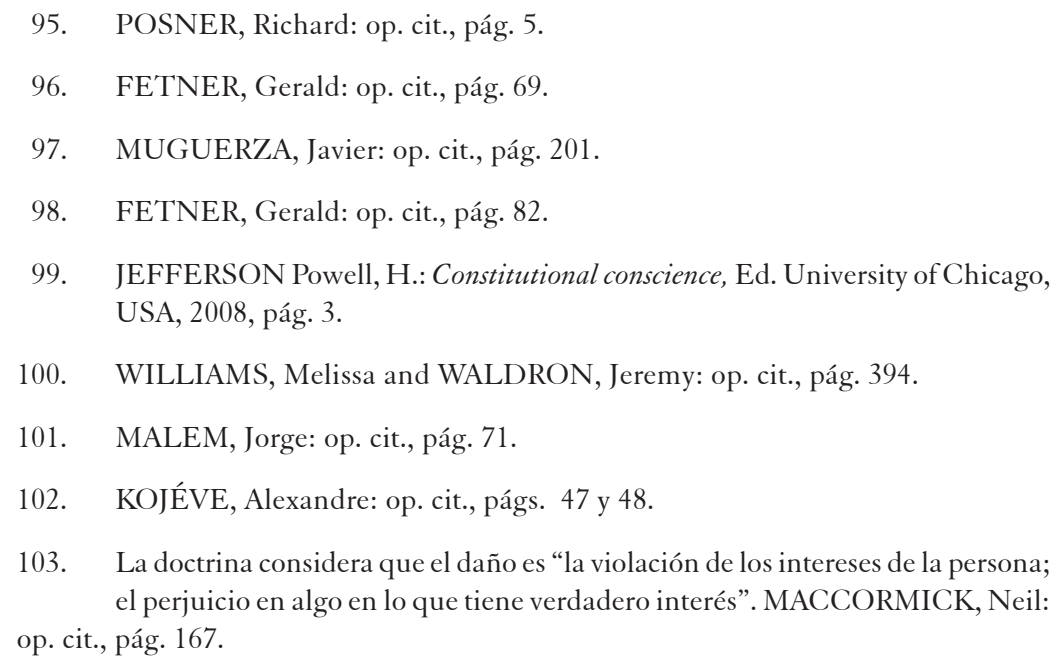


La prueba de daño se refiere a un balance específico que debe realizarse al aplicar a un caso concreto, una excepción fundada en el interés público ${ }^{104}$.

Los elementos que el juez debe considerar para analizar y reconocer si hubo un daño, son los siguientes ${ }^{105}$ :

1. Confusión de las leyes con fundamentos paternalistas y con esto se constituye, la supuesta justificación de leyes que reprimen cualquier inmoralidad.

2. Confunde la legitimidad de la represión de la indecencia con la supuesta justificación de la represión de acciones inmorales ejecutadas en privado.

3. No ofrece prueba alguna de porqué se ha de influir en las personas, pera que se comparten moralmente mediante la imposición estatal de un mal ${ }^{106}$.

Por lo que el principio del daño "presupone tanto la determinación previa de cuáles han de ser los intereses privados que han de protegerse, como una concepción acerca del bien público"107.

Con lo anterior, se legitima por sí mismo "la exigencia legal de un valor moral fundamental: el de proteger a las personas de daños infligidos intencionalmente por otros" ${ }^{108}$.

Por otro lado, y no menos importante, es que los jueces deben ejercer su función bajo los principios de imparcialidad y el de objetividad $^{109}$.

104. LÓPEZ Ayllón: Democracia y derecho a la información, TEPJF, México, 2005, pág. 249.

105. BICKEL, Alexander M.: op. cit., págs. 36 y 173.

106. MALEM, Jorge: op. cit., págs. 69 y 70. HART, H.L.A.: op. cit., págs. 81-83.

107. MALEM, Jorge: op. cit., pág. 75. FAÚNDEZ Ledesma, Héctor: op. cit., págs. 582, 584 y 585 .

108. MACCORMICK, Neil: op. cit., págs. 170 y 171.

109. BICKEL, Alexander M.: op. cit., págs. 50 y 55. Cfr, SOEHARNO, Jonathan: The integrity of the judge, Ed. Ashgate, England, 2009.

Facultad de Derecho y Ciencias Sociales - Universidad de Valparaíso - Chile 
Isabel Trujillo valora a primera instancia, a la imparcialidad desde el punto de vista jurídico:

"La imparcialidad se ha configurado tradicionalmente como una característica estructural del derecho. Se sitúa dentro del juicio de autoridad y constituye un criterio interno de articulación, conectado con una exigencia de justicia en relación con los sujetos implicados" ${ }^{110}$.

Esta autora explica que existen dos conceptos primarios de imparcialidad: "el primero tiene que ver con la objetividad del juicio y considera imparcial a quien juzga de manera objetiva, sin prejuicios o distorsiones; el segundo tiene que ver con el equilibrio cuando se confrontan intereses opuestos, poniendo el acento sobre un sentido colateral de imparcialidad: la ausencia de favoritismo o de partidismo" 111 .

Ronald Dworkin considera a la objetividad como la cualidad suficiente y plena de la interpretación de la ley y de comprobación de los hechos contrastados por las partes, despejada hasta lo humanamente posible de cualquier asomo de subjetividad o de relatividad que pueda entorpecer la función del juzgador, en agravio de la impartición de justicia ${ }^{112}$.

Pero no sólo bastan estos principios de actuación judicial, sino que el juez debe adminicular y correlacionar los hechos con la normatividad correspondiente ${ }^{113}$. Este acto racional le permitirá al juez aplicar de manera concreta normas lógicas y razonables. Pero esta extensión del uso de la razonabilidad "está limitada por la exigencia de imparcialidad, que excluye la posibilidad de hacer valer en la argumentación moral ventajas posicionales individuales grupales" ${ }^{114}$.

110. TRUJILlO, Isabel: Imparcialidad, Ed. UNAM, México, 2007, pág. 2. FAÚNDEZ Ledesma: Héctor, op. cit., pág. 685.

111. Ïdem, pág. 3. Vid, SALDAÑA Serrano, Javier: Virtudes del juzgador, Ed. SCJN, México, 2007, Págs. 48-51.

112. DWORKIN, Ronald: Los Derechos en serio, Ed. Ariel, 1990, págs. 154 y ss. POSNER, Richard: op. cit., pág. 89.

113. JEFFERSON Powell, H.: op. cit., págs. 10 y 11.

114. Ídem, pág. 50.

Revista de Ciencias Sociales - Número 62 (2013) - Universidad de Valparáíso - ISSN 0716-7725-Valparaíso, Chile 
El juez podrá interpretar las normas conforme a un marco establecido y atenuar las incertidumbres o lagunas legales ${ }^{115}$, "parece adecuado describir esa experiencia como el intento de reconocer algo que espera reconocimiento, más que como un elección deliberada”"116. Las normas son impuestas por el legislador y sólo se espera la correcta aplicación de las mismas ${ }^{117}$.

Pero un juez puede cuestionar, si una norma es justa o sólo debe aceptarla por su origen democrático y sobre todo, un juzgador debe o puede poner en duda la legitimidad de la norma. En algunos casos, al juez le puede llegar a producir repugnancia la obligación de aplicar una norma contraria a sus creencias. Aquí se produce un choque entre el derecho y sus convicciones. Es bajo estas situaciones cuando se pone a prueba su destreza y objetividad al interpretar y emplear la norma ${ }^{118}$.

La consecuencia será el reconocimiento de que al interpretar las reglas de derecho en algunos casos, se tendrá que elaborar o generar una articulación natural, que de alguna manera, parece ir más allá de ella, pero no es precisamente una suplantación legislativa ni un acto de creación normativa.

"El concepto de discreción, en su sentido ordinario, alude a la posibilidad de tomar decisiones dentro de un área abierta por patrones establecidos por alguna autoridad particular. Puede sólo como sensatez o buen juicio, en un contexto no suficientemente claro, pero también como la capacidad, en un contexto preciso, de una autoridad superior cuyas decisiones no pueden ser revisadas por otra autoridad"119.

Es oportuno regresar al tema principal, cómo el juez deberá sancionar aquella conducta que violó la norma.

115. POSNER, Richard: op. cit., págs. 8 y 11.

116. SALMERÓN, Fernando: op. cit., pág. 93.

117. FETNER, Gerald: op. cit., págs. 71 y 73.

118. MUGUERZA, Javier: op. cit., págs. 203 y 208.

119. SALMERÓN, Fernando: op. cit., págs. 102 y 109.

Facultad de Derecho y Ciencias Sociales - Universidad de Valparaíso - Chile 


\section{La moral pública y los jueces}

La primera etapa de este proceso será acusar formalmente al sujeto y presentar las pruebas de cargo y descargo, para valorar si ese acto se cometió, bajo qué situación y porqué se llevó a cabo. Posteriormente, el juez analizará si en ese comportamiento hubo una inmoralidad, o sea, un agravio contra la sociedad. Con estos elementos, el juez deberá decidir si sancionará y con ello, calificar esa conducta impropia $^{120}$. Esta decisión legal, el juez la puede elaborar desde tres perspectivas: el liberal (permisivo), el moral público (punitivo) y el de la tolerancia (determinar las reglas para ejercer este comportamiento). Sin embargo, qué sucede si el acusado argumenta que su conducta la produjo como una forma de libertad individual (artística, expresión política, laboral, etc.).

Primero, desde el punto de vista liberal, se deben determinar de los bienes dignos de ser protegidos. El Estado debe permanecer neutral respecto de las concepciones particulares de lo "bueno"121. La función del Derecho sería crear las condiciones necesarias para el florecimiento de lo individual. Lo importante, es rechazar el absolutismo de la libertad.

El juez deberá sopesar entre los derechos inalienables y las normas generales, que permiten la convivencia pacífica de la comunidad $^{122}$. Analicemos los argumentos del acusado de violar las normas.

La Declaración de los Derechos del hombre y del Ciudadano indica que "La ley no puede prohibir más que las acciones dañosas para la sociedad"; por lo que debemos evaluar si esa conducta realmente ocasionó un daño a la comunidad, para esto tiene los elementos del principio de daño (ya citado anteriormente).

Otro principio que este individuo puede invocar en su actuar, es el de su autonomía individual e inviolabilidad de la persona; con esto,

\footnotetext{
120. POSNER, Richard: op. cit., págs. 85-86 y 88.

121. DWORKIN, Ronald: Freedom's law, op. cit., pág. 238. JEFFERSON Powell, H.: op. cit., pág. 27.
122. HART, H.L.A.: op. cit., pág. 48. BICKEL, Alexander M.: op. cit., págs. 205- 206.

Revista de Ciencias Sociales - Número 62 (2013) - Universidad de Valparáíso - ISSN 0716-7725-Valparaíso, Chile 
sería “posible dar una fundamentación racional completa de los derechos humanos dentro de un marco de un discurso moral" 123 .

Segundo, si el juez considera que se debe castigar al acusado, porque con su conducta infringió una ofensa a la sociedad ${ }^{124}$. Por un lado, los jueces deben hacer caso omiso a sus opiniones morales, más bien, deben manifestar tolerancia hacia ideas incompatibles con él. Por otra parte, el tribunal no debe tolerar las violaciones a la ley, incluso si el juez personalmente siente que podría tolerar el acto ofensivo ${ }^{125}$.

Si la defensa del procesado alega la libertad de expresión como fuente de su comportamiento, pero el juez no la considera relevante, podrá sancionar con base en la prueba del interés público ${ }^{126}$.

El propósito de la libertad no es la autorrealización individual, sino más bien la preservación de la democracia y del derecho de un pueblo, en tanto pueblo, a decidir qué tipo de vida quiere vivir ${ }^{127}$.

Aquí los argumentos individuales no pueden estar sobre el interés público.

"El argumento se debilita en el caso de conductas únicamente ofensivas, pero al menos se puede decir que las formas más graves de manifestaciones públicas ofensivas inhiben la libertad de atender sus asuntos en sitios públicos de la gente comúnmente sensible"128.

El tercer escenario judicial es construir una sentencia que permita al acusado ejercer esa conducta, sin dañar al resto de la comunidad ${ }^{129}$.

123. GARZÓN Valdés, Ernesto: "Derecho y moral”. En Vázquez, Rodolfo: Derecho y moral, op. cit. Pág. 49.

124. JEFFERSON Powell, H.: op. cit., pág. 83.

125. WILLIAMS, Melissa and WALDRON, Jeremy: op. cit., pág. 179.

126. Ídem, pág. 336. Esta prueba se refiere a aquellas circunstancias excepcionales en las que la protección a la vida privada puede ser subordinada al interés público. Vid, FISS, Owen: op. cit., págs. 23 y 52. ACKERMAN, Bruce: op. cit., pág. 234.

127. LÓPEZ Ayllón: op. cit., pág. 249.

128. MACCORMICK, Neil: op. cit., pág. 168.

129. POSNER, Richard: op. cit., págs. 81-82 y 93-121. JEFFERSON Powell, H.: op. cit., págs. 93 y 96.

Facultad de Derecho y Ciencias Sociales - Universidad de Valparaíso - Chile 
Por lo que se pueden marcar o señalar lugares especiales y horas específicas, que adviertan a la población ${ }^{130}$. Con esta resolución, se equilibran ambas posiciones e intereses “...desde la perspectiva liberal no deja de ser una línea en que se cruzan los bienes protegidos por las instituciones colectivas y los derechos individuales" ${ }^{131}$.

Aquí, la tolerancia es una virtud que dirige el poder gobernante en la fabricación de tales alojamientos con precisión cuando la neutralidad constitucional y la universalidad no requieren esto.

La tolerancia se debe utilizar como un estándar y un medio para juzgar, donde las fronteras de la vida común son encontradas ${ }^{132}$. De esta manera, la tolerancia describe el camino por la que conceptos diferentes pero "razonables" moralmente, son aceptados mutuamente, dentro del marco de una sociedad justa ${ }^{133}$.

Otra posible forma para resolver esta clase de asuntos, es basado en los casos precedentes ${ }^{134}$. Con esto, el juez buscará una opinión externa y resolverá de conformidad con las sentencias emitidas por sus pares ${ }^{135}$.

El papel de las autoridades no es remover las causas de la tensión eliminando el pluralismo, sino garantizar que cada uno de esos grupos actúen de manera tolerante con los demás ${ }^{136}$.

Sin embargo, que cualquier decisión que tome un juez en esta clase de asuntos tendrá consecuencias políticas ${ }^{137}$. Lo importante, es no

130. Como nudismo, zonas rojas, etc. Vid, FAÚNDEZ Ledesma, Héctor: op. cit., págs. 594 y 595 .

131. SALMERÓN, Fernando: op. cit., pág. 90.

132. WILLIAMS, Melissa and WALDRON, Jeremy: op. cit., págs. 223 y 347.

133. Ídem, págs. 177 y 415.

134. Cfr, GERHARDT, Michael J.: The power of precedent, Ed. Oxford, New York, 2008.

135. POSNER, Richard: op. cit., págs. 144, 154, 183 y 184.

136. FAÚNDEZ Ledesma, Héctor: op. cit., pág. 572.

137. JEFFERSON Powell, H.: op. cit., págs. 47, 52 y 53.

Revista de Ciencias Sociales - Número 62 (2013) - Universidad de Valparáíso - ISSN 0716-7725-Valparáiso, Chile 
obstruir el libre desarrollo de los individuos y la obtención de la felicidad (sin dañar a nadie, pues sus derechos no están sobre los de otros, sino que deben de convivir); pero por otro lado, deben de regir normas que permitan y fortalezcan "la cohesión social o la solidaridad dependen de ciertos preceptos morales comunes que pueden constituir un consenso moral" 138 .

En la actualidad, los juzgadores están llamados a realizar un papel decisivo para la democracia, pues ellos son los garantes de los derechos fundamentales y dar continuidad constitucional y legal a los actos de los órganos del poder público ${ }^{139}$.

Para finalizar esta monografía se presentarán un conjunto conclusiones, que resumen las aristas del tema tratado.

\section{Conclusiones}

1. Este trabajo sostiene la imposibilidad de desvincular el derecho y la moral, porque existe una relación simbiótica entre ambas ${ }^{140}$. Esto se ejemplifica por que las normas provienen de una aceptación general o una costumbre social, que se materializa en leyes que tienen un carácter general; por lo que todos los sujetos deberán de obedecerlas (imposiciones mayoritarias positivadas).

"La base está formada por la pretensión de corrección. Esto solo tiene carácter definitorio para el sistema jurídico en su conjunto, parte de que su carácter calificativo se vuelve obvio si el sistema jurídico se ve como un sistema de procedimientos, desde el punto de vista de un participante" ${ }^{\prime 14}$.

Esta conexión entre derecho, patrones morales y principios de justicia, puede ser en su señalamiento "tan arbitrario o tan necesario, como la conexión que hacen algunos juristas entre derecho y sanción”142.

138. MACCORMICK, Neil: op. cit., pág. 180.

139. OROZCO Henríquez, Jesús: "Judicialización de la política y legitimidad judicial”. En Vázquez, Rodolfo: Corte, jueves y política, op. cit., pág. 39.

140. ALEXY, Robert: op. cit., Págs. 115 y 116.

141. Ídem, págs. 133 y 150

142. SALMERÓN, Fernando: op. cit., Pág. 86.

Facultad de Derecho y Ciencias Sociales - Universidad de Valparaíso - Chile 
2. La moral pública solo puede prevalecer sobre la libertad individual cuando es necesario evitar o remover expresiones ofensivas, que lesionan los derechos de otros. Pero, poner en la balanza la libertad individual y la moral pública no significa que tengamos que inclinarnos a favor de la moralidad; este es un proceso que una sociedad democrática debe emprender con especial cuidado y, por consiguiente, los tribunales deben actuar con suma cautela en la ponderación de estos bienes jurídicos ${ }^{143}$.

3. La imposición de tipos de conducta prescriptivas, realmente no determinan la conducta; sino que el individuo puede evaluarlas, ajustarlas, adoptarlas o desecharlas, pudiendo crear un sistema descriptivo de conductas,

"Los verdaderos valores morales son aquellos que se realizan en las decisiones libres y exentas de coacción de las personas, que actúan conscientemente de acuerdo con principios a los que se someten voluntariamente. La verdadera virtud moral no está constituida por una conformidad aparente hacia modelos de conducta externamente impuestos y respaldados por las amenazas de los castigos legales. Está constituida por el libre autocompromiso con modelos de conducta y valores internamente aceptadas y por decisiones motivadas por este autocompromiso" ${ }^{144}$.

El efecto al establecer normas es fijar límites a nuestra elección, pero no determina nuestra elección.

4. Desde una posición liberal, "el Estado debe limitarse a diseñar instituciones que faciliten la persecución individual de esos planes de vida y la satisfacción de los ideales de virtud que cada uno sustente e impidiendo la interferencia mutua en el curso de tal persecución” ${ }^{145}$. Sin embargo, la libertad y la autonomía deben tener controles; no son bienes del que se pueda gozar de manera absoluta.

143. FAÚNDEZ Ledesma, Héctor: op. cit., págs. 607 y 750.

144. MACCORMICK, Neil: op. cit., pág. 165.

145. Vid, NINO, Carlos S.: "El principio de autonomía de la persona", en Ética y Derechos Humanos, Ed. Astrea, Buenos Aires, 1989, págs. 199-236.

Revista de Ciencias Sociales - Número 62 (2013) - Universidad de Valparaíso - ISSN 0716-7725-Valparaíso, Chile 
“...resulta esencial para garantizar el equilibrio entre un Estado cada vez más omnipresente e individuos cada vez más dependientes de las formas jurídicas de organización de la sociedad a la que pertenecen. La existencia o inexistencia de ese equilibrio pondrá de manifiesto las distancias entre los regímenes democráticos en que el individuo encuentre el espacio para la constitución de su propio plan de vida según se lo determine la autonomía de su propia conciencia y sólo dentro de los límites en los que no afecte igual derecho de los demás"146.

5. Las libertades individuales no deben originar un libertinaje moral; hay valores y principios que permiten la unidad y la cohesión de la sociedad. El no respetar los valores lleva a la polución y erosión de la sociedad $^{147}$.

6. Uno de los principios que debe respetar el Estado, es el de la autonomía individual; en el sentido de producir seres capaces de adoptar evaluaciones personales con respeto al deber de obediencia a las leyes.

7. La ponderación individual nos permite inferir si las normas son buenas, correctas, justas, si simbolizan los valores personales, etc. El punto es discernir, si aquella normatividad me representa y/o si debe aceptarse llanamente, aunque no concuerde con mi identidad.

Por lo que siempre habrá personas inconformes por las imposiciones hechas por otros (aunque sea democráticamente) ${ }^{148}$. Pues como afirma, el maestro Ernesto Garzón Valdés: "No todo principio o juicio moral es una norma jurídica, pero toda norma jurídica que tiene un rol de razón operativa en el razonamiento práctico es un razonamiento moral especial" ${ }^{149}$.

Pero el sujeto que se sienta agraviado por esas imposiciones normativas, debe aceptar y reconocer que las leyes legítimas contienen

146. BAZTERRICA, Gustavo M.: La ley, agosto 29 de 1986, t. 1986-D, pág. 547.

147. MALEM, Jorge: op. cit., pág. 72.

148. Un punto relevante, es que cualquier persona que esté contra alguna norma, pueda manifestarlo sin que sea sancionada.

149. GARZÓN Valdés, Ernesto: “Derecho y moral”. En Vázquez, Rodolfo: Derecho y moral, op. cit., pág. 25.

Facultad de Derecho y Ciencias Sociales - Universidad de Valparaíso - Chile 
intrínsecamente valores morales sociales; por lo que si desea convivir en la misma sociedad debe comportarse conforme a las mismas, y en caso de no garantizar su cumplimiento, deberá atenerse a la sanción (previamente establecida); esto con el objeto de que la conducta sea castigada y, se pueda restablecer el orden y por otro lado, garantizar la cohesión de una comunidad: "ninguna sociedad mantener su cohesión si no cuenta con una estructura jurídica que establezca dogmáticamente qué es lo que en ella considera justo"150.

8. En una sociedad pluralista, se debe permitir el disenso; la libertad se debe ejercer con responsabilidad, sin perjudicar a las demás personas ${ }^{151}$. En el marco del pluralismo, la tolerancia es una actitud de los individuos (o grupos) de uno hacia el otro, ejercido sobre su tentativa de alcanzar sus objetivos, más que una norma de acción estatal o un principio constitucional ${ }^{152}$. Deben existir elementos de ayuda mutua y lealtad común, que nos lleven a buscar el uno al otro, que en conjunto servirá para crear y mantener las estructuras de cuidado para los asuntos de atención y preocupación común ${ }^{153}$.

9. El papel que desarrolla el juez es fundamental para establecer límites y conservar la libertad, para que no se produzca algún abuso ${ }^{154}$; y por otro lado, el juez debe entender, razonar y aplicar, la norma de manera imparcial y objetiva ${ }^{155}$.

10. Las perspectivas democráticas dependen de la mejora del carácter moral de los individuos por los cambios. Sólo nuestros intereses se pueden limitar por el daño que puede ocasionarse, lo que permite la

150. Ibídem, pág. 146.

151. Vid, SCANLON, T.M.: The difficulty of tolerance, Ed. Cambridge, USA, 2008.

152. WILLIAMS, Melissa and WALDRON, Jeremy: op. cit., págs. 23 y 179.

153. BOBBIO, Norberto: El tiempo de los derechos, Ed. Sistema, Madrid, 1990, págs. 243-256.

154. BICKEL, Alexander M.: op. cit., pág. 264.

155. JEFFERSON Powell, H.: op. cit., pág. 121. FETNER, Gerald: op. cit., pág. 3.

Revista de Ciencias Sociales - Número 62 (2013) - Universidad de Valparáíso - ISSN 0716-7725-Valparáiso, Chile 
coacción del Estado; pero una sociedad no debería cultivar una cultura de permisión excesiva hacia los grupos que subvaloran la igualdad y la libertad de todos sus miembros ${ }^{156}$.

\section{Bibliografía}

ACKERMAN, Bruce: We the people. Foundations, Ed. Harvard press, USA, 1991.

BARNETT, Randy: Restoring the lost constitution, Ed.Princeton press, USA, 2004.

BERLIN, Isaiah: Four essays on liberty, Ed. Oxford, England, 1969.

BICKEL, Alexander M.: The least dangerous power, Ed. Yale, USA, 1986.

BIX, Brian H.: Diccionario de teoría jurídica, Ed. UNAM, México, 2009.

BOBBIO, Norberto, Dicionário de política, Ed. UnB, $11^{\text {a }}$. Edición, Brasil, 1983.

BOBBIO, Norberto, El tiempo de los derechos, Ed. Sistema, Madrid, 1990.

COVARRUBIAS DUEÑAS, Jesús: "Valores y principios constitucionales de la justicia penal electoral en México", Revista Mexicana de

Justicia, No 5, México, 2003.

CRAGG, Wesley: The practice of punishment, Ed. Routledge, London, 1992.

DWORKIN, Ronald: Los Derechos en serio, Ed. Ariel, España, 1990.

DWORKIN, Ronald: Freedom's law, Ed. Harvard, Cambridge, 1996.

FALLON, Richard Jr.: The dynamic constitution, Ed. Cambridge, USA, 2004.

FAÚNDEZ LEDESMA, Héctor: Los límites de la libertad de expresión, Ed. UNAM, México, 2004.

FRANCO DEMARCHI, Aldo Ellena: Diccionario de sociología, Ed. Paulinas, Madrid, 1986.

FETNER, Gerald: Ordered liberty, Borzoi books, USA, 1983.

FISS, Owen: Libertad de expresión y estructura social, Ed. Fontamara, México, 2004.

156. WILLIAMS, Melissa and WALDRON, Jeremy: op. cit., pág. 18.

Facultad de Derecho y Ciencias Sociales - Universidad de Valparaíso - Chile 
GALLINO, Luciano: Diccionario de sociología, Ed. Siglo XXI, México. GARGARELLA, Roberto: "El carácter igualitario del republicanismo" en Isegoria, $\mathrm{N}^{\circ}$ 33, 2005.

GARLAND, David: La cultura del control, Ed. Gedisa, España, 2001.

GERHARDT, Michael J.: The power of precedent, Ed. Oxford, New York, 2008.

JEFFERSON POWELL, Herbert: Constitutional conscience, Ed. University of Chicago, USA, 2008.

JOYCE, Richard: The evolution of morality, The MIT press, USA, 2006.

HART, H.L. A.: Law, liberty and morality, Ed.Vintage, USA, 1963.

HINDE, Robert A.: Why good is good. The sources of morality, Ed. Routledge, USA, 2002.

KOJÉVE, Alexandre: La noción de autoridad, Ed. Nueva visión, Buenos Aires, 2005.

LARMORE, Charles: The autonomy of morality, Ed. Cambridge, USA, 2008.

LINZ, Juan J.: Problems of democratic transition and consolidation, Ed. The Johns Hopkins University Press, USA, 1996.

LÓPEZ, Ayllón: Democracia y derecho a la información, TEPJF, México, 2005.

MACKIE, J. L.: Ethics. Inventing the right and wrong, Ed. Penguin, USA, 1990.

MELOSSI, Dario: El Estado del control social, Ed. Siglo XXI, México, 1982.

OSSORIO, Manuel: Diccionario de ciencias jurídicas, Ed. Dastancan, Guatemala, 2004.

NINO, Carlos S.: Ética y Derechos Humanos, Ed. Astrea, Buenos Aires, 1989.

NOHLEN, Dieter: El contexto hace la diferencia: reformas institucionales y el enfoque histórico-empírico, Ed. UNAM, México, 2003.

PANICHAS, George: Sex, morality and the law, Ed. Routledge, Great Britain, 1997.

PERRY, Michael J.: Constitutional rights, moral controversy and the Supreme Court, Ed. Cambridge, USA, 2009.

POSNER, Eric A.: Law and social norms, Ed. Harvard press, USA, 2002.

POSNER, Richard: How judges think, Ed. Harvard press, USA, 2008. 
RAWLS, John: Liberalism political, Ed. Harvard, Cambridge, 1996. RAZ, Joseph: The morality of freedom, Ed. Oxford, New York, 1988.

ROTHBARD, Murray N.: The ethics of liberty, Ed. New York University press, USA, 1998.

SALDAÑA SERRANO, Javier: Virtudes del juzgador, Ed. SCJN, México, 2007.

SCANLON, T.M.: The difficulty of tolerance, Ed. Cambridge, USA, 2008.

SCHOECK, Helmut: Diccionario de sociología, Ed. Herder, Barcelona, 1981.

SCRUTON, Roger: The Palgrave Macmillan Dictionary of Political Thought, Ed. Palgrave Macmillan, USA, 2007.

SOEHARNO, Jonathan: The integrity of the judge, Ed. Ashgate, England, 2009.

TEDFORD, Thomas L.: Freedom of speech in the United States, Ed. Strata, USA, 2009.

TOCQUEVILLE, Alexis: La democracia en América, Ed. FCE, México, 1957.

TRUJILLO, Isabel: Imparcialidad, Ed. UNAM, México, 2007.

VÁZQUEZ, Rodolfo (compilador): Derecho y moral, Ed. Gedisa, Madrid, 1998.

VÁZQUEZ, Rodolfo (compilador): Corte, jueces y política, Ed. Fontamara, México, 2007.

WILLIAMS, Melissa \& WALDRON, Jeremy: Toleration and its limits, Ed. New York University press, New York, 2008.

WINDLESHAM, Lord: Politics, punishment and populism, Ed. Oxford, USA, 1998.

Diccionario Jurídico Mexicano, Ed. UNAM, México, 1982.

Diccionario de la Real Academia de la Lengua Española.

Black's Law, Ed. West, USA, 2009.

\section{Recursos electrónicos:}

http://ciberconta.unizar.es/leccion/sociodic/tododic.pdf

http://www.law.yale.edu/documents/pdf/Comella_Do_Constitutional_ Rights_Bind_Private_Individuals.pdf

Facultad de Derecho y Ciencias Sociales - Universidad de Valparaíso - Chile 
http://www.uns.edu.ar/programma/ediciones/edicion1/07_edicion1.pdf http://enciclopedia_universal.esacademic.com/19830 